\title{
ANTROPOLOGIA APLICADA
}

Sérgio Alves Teixeira

Não só os especialistas em ciências sociais, mas a generalidade dos indivíduos com mediana formação escolar está ciente de que, por maiores diferenças que apresente, a cultura do homem contemporâneo possui mais elementos universais do que em qualquer época passada. E na época presente que podemos, com real propriedade, falar èm têrmos de História Universal, com a conotação de os fatos e acontecimentos da quase totalidade dos homens interessarem aos demais em muito larga escala. E assim não poderia deixar de ser, não só pelo que decorre diretamente da organização econômica, social e política da civilização atual, mas também pela aproximação, quase intimidade, em que vivem os homens, pelos meios de transporte e comunicação.

Dentre os elementos que podem ser considerados como universais na trama cultural que forma a civilização contemporânea a orientação pragmática e a busca, quase obsessiva, de bem-estar por indivíduos e instituições devem ser incluídos. Aqui reside a chave para a Antropologia Aplicada. Vejamos como se põe a questão. E fora de discussão que qualquer conhecimento, em si só, já tem aplicação. Nesse ponto os conhecimentos da Antropologia de há muito têm aplicação, como o haver demonstrado, com rigor científico, a falsidade de todos os determinismos simplistas, a falsidade das supostas inferioridade e superioridade raciais, a demonstração da existência, em número quase ilimitado, de respostas alternativas culturalmente determinadas, que através dos tempos o homem tem encontrado para satisfazer suas necessidades, mesmo as de ordem natural, reduzindo assim às devidas proporções aquilo que no comportamento humano e cultural deve ser visto como 
inerente à natureza humana, convidando à tolerancia para com outras tradições culturais e seus membros e ao abandono do etnocentrismo.

Mas quando se fala em Antropologia Aplicada pensa-se noutros têrmos, como aumento de produção, adoção de novas técnicas e produtos, abrandamento ou eliminação de tensões no relacionamento humano, melhoria de saúde e condições sanitárias, mais eficiência na educação.

Aqui é que entra a orientação pragmática e busca de bemestar mencionados linhas atrás como chave para a aplicação da Antropologia. De fato, o pragmatismo, sendo uma das orientações da civilização contemporânea, exige que tudo o que se faz tenha aplicação prática na solução dos problemas da vida cotidiana. $O$ antropólogo não ficou imune a tal pensamento e buscou aplicar «no sentido prático» seus conhecimentos.

Como não poderia deixar de ser, esta situação refletiu-se no ensino da Antropologia, como pode ser constatado na maioria dos manuais e programas básicos, onde é usual encontrar-se um capítulo justamente intitulado Antropologia Aplicada. E não é só. Para alunos em estágios mais desenvolvidos a praticidade pode ser muito mais enfatizada. Eu mesmo, êste ano, num programa para alunos em $2^{\circ}$ ano de estudos de Antropologia, desenvolvo um programa com tal orientação. Dêsse programa talvez o capitulo mais de acôrdo com êsse pragmatismo seja a abordagem dos valôres brasileiros que são obstaculizantes e estimulantes para o desenvolvimento econômico. Isto decorre do fato de me incluir entre aquêles que acreditam ter as ciências sociais muito a contribuir para o desenvolvimento nacional, uma vez que muitos fatôres do nosso atraso e subdesenvolvimento devem ser buscados na nossa cultura e sociedade.

O pragmatismo não só fêz com que antropólogos e professôres de Antropologia buscassem aplicar seus conhecimentos, mas levou outros indivíduos, especializados e responsáveis por outras atividades, como nos campos atrás mencionados, a se utilizarem dos conhecimentos antropológicos para maior eficiência de suas próprias atividades, que, em última análise, visam conseguir o tão almejado bem-estar.
Be a Antropologia como elênela fó recente, mail reeente ainda 6 a Antropologia Aplioada, ehegando alguss auterea preeisarem no tempo o seu surgimento: 1021, quande oeorreu o teroeiro levante ashanti (na atual Ghana), contra a admi. nistrag̨ĭo britânica no conheoido episódio do Assento Dourade Fol solucionado o impasse graças aos esforg̨os do eapitî̃o theน. tray, antropólogo governamental, que demonstrou â autonis dades o verdadeiro significado do Assento Dourade para as ashantis." Sem esquecer a relatividade de datas como esias, ela nos lembra mui enfàticamente quão recente of a Antropolesila Aplicada, o que é reforçado se pensarmos que a Sociedade de Antropologia Aplicada, nos Estados Unidos, data de 1941, Fof ser de aplicação recente, não só muitos antropólogos ainda nî̀ a admitem, como também muitos daqueles que com real pres veito poderiam utilizar as descobertas da Antropologia, para os primeiros é conspurcar o estudo e pesquisa, sua utilisaelle prática. Os que assim pensam não só são minoria, 60 me tornam cada vez mais minoria. Os outros, os chefes de em. prêsa, administradores, planejadores opõem resistênela, nhlo por que não vejam mérito na aplicação dả Antropologia, mai pelo bom senso, pelo senso comum que a generalidade da pea: soas com tais responsabilidades estão dotadas. Eles mesme日 empregam muitos princípios da Antropologia, só que de min neira assistemática e sem rigor científico. Mas à medida que passa o tempo e os problemas que são resolvidos pelo tbem senso» tornam-se mais complexos, se quer mais efielênela, fë corre-se a especialistas, dotados não só de bom senso, mai de um conhecimento científico requintado. $\mathrm{E}$ isto não ถอ đถิ com a Antropologia, mas com tôdas as ciências sociais.

Usam-se as descobertas da Antropologia, com todo o riger científico, sem ser através de antropólogos, o que pode ser dia: pensável, e mesmo sem consciência para muitos, de onde asilu aquilo que emprega com efetivo resultado. Assim temol que

1 - An Introduction to Social Anthropology, D. N. Majundar e $T_{1} \mathrm{~N}_{1}$ Madan, 6a ed., 1967, Asia Publishing House, p. 38.

2 - Antropologia, C. Kluckhohn, 3a ed., 1957, Fondo de Cultura Heen nómica, p. 185. 
a propaganda, tão fundamental na sociedade industrial, utili za-se muito de duas constatações da pesquisa antropológica: A existência de uma cultura aberta e outra encoberta em qual= quer sociedade humana e a aceitação de elementos novos por motivações de prestígio. Basta ler, ouvir ou ver para constatarmos tal fato. Os especialistas em propaganda procuram descobrir as motivações que determinam a ação e comportamento daqueles que constituem seu mercado em potencial, e que estão ocultas na cultura encoberta. Feito isto uma simples insinuação pode ser o suficiente, para a consecução de seus objetivos, como aquela propaganda da Suita: «Você está preparada para usar biquini no próximo verão?» E com relação a prestígio? Basta vermos quem divulga os produtos. São os que desfrutam de prestígio popular. A réplica à Suita veio através de Pelé: «Pelé pula, Pelé corre, Pelé chuta, Pelé vibra, Pelé encanta. Pergunte a Pelé se êle substituiu o açúcar?»

Mas nosso tema é Antropologia Aplicada, explìcitamente, por especialistas antropólogos. Vejamos isto de perto.

Anteriormente já indicamos alguns dos muitos e variados campos em que a Antropologia pode ser aplicada e isto pode levar algum mal avisado ou mal intencionado a perguntar se a Antropologia tem a vara de condão para solver tantas e tão graves preocupações do homem da sociedade industrial. Evidente que a resposta é negativa. Mas pela amplidão dos seus pontos de referência, pelo método global de enfocar a cultura, o que faz com exclusividade dentre as ciências sociais, a Antropologia está apta a contribuir, de modo muito significativo, como ciência auxiliar, na solução satisfatória de problemas existentes nesses campos.

Do próprio episódio sugerido para marcar o início da Antropologia Aplicada podemos perceber aquêle que foi o primeiro e um dos maiores campos para a aplicação da Antropologia. Referimo-nos, como é fácil de perceber, à situação de contato entre tradições culturais muito distintas, como a decorrente do irreversível avanço da civilização. Nesta situação os choques culturais são axiomas. Muitos hábitos, valôres e orientações culturais são por demais contraditórios para que

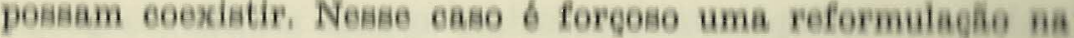

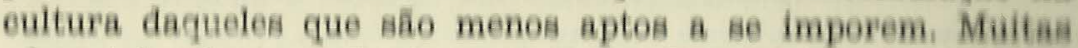
vênes tal reformulağ̣o faz-se a custa de perda e abandono di prátieas e valôres básieos para o grupo, o que pode proveear perdas irreparáveis, com profundos reflexos na harmenia ลa dal e cultural do grupo em questĩo. Isto fol demenatrada f

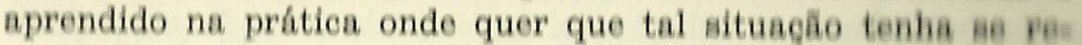
petido, evidente que sempre com as variaçôs deeorrentes dia variáveis em jôgo em cada caso. Nestas cireunstânelä ḋ quas

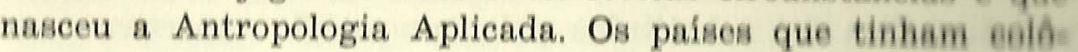
nias aprenderam a lição e utilizaram a antropologia em territórios coloniais. Países como a Rússia, Méxiee, 1Hátada Unidos e Brasil, em seus próprios territórios.

Em relação ao problema no Brasil penso que o estudo mail recente é o interessante Aculturação Indigena, de Hegan Hehin: den, editado êste ano. Nesse trabalho o autor nẵo 自 tema em seus aspectos teóricos, mas especialmente a altuacho concreta para o índio e sua cultura, resultante do avaneอ do homem e da cultura brasileira e, como diz. o autor, еврега qин seu trabalho ccntribua para o estabelecimento de norma mili racionais no campo da política indigenista.

Para abrandar tajs choques, para ajudar na reformulnent cultural o auxílio da Antropologia pode ser indispensivivel, princípio desenvolvido pela Antropologia é que quande primido ou eliminado um elemento cultural, em especial qุแand através da fôrça, deve-se encontrar um substituto para 9 mеі mo se se pretende diminuir a perda cultural e reduzir a dean ganização e possibilidades de contra-reações. Essse prineiplo ten. grande valia nos casos de mudança cultural dirigida.

$\mathrm{Na}$ África Negra um padrão muito difundido $\delta$ o preeto de noiva, que muitas vêzes foi considerado repugnante por mili sionários, chegando mesmo a ser proibida a transferenela d gado e outros bens da família do noivo para à da nolva, 盛 perceberem que muito longe de ser uma compra da nolva, ta transferência de bens é uma eficiente medida que vils gurar a estabilidade do casamento e da família. Tal proiblệ: mostrou-se tão negativa em seus resultados que fol anuladi 
Coube aos antropólogos demonstrar o real sentido do preço de noiva.

Na Nova Guiné entre os papuas a caça de cabeças humanas era uma instituição consagrada. Um jovem se afirmava, obtinha credenciais para um bom casamento e sucesso na vida econômica praticando a caça de cabeças. Enfàticamente combatida pelos holandeses, a solução foi encontrada levando os papuas a. caçarem javalis, ${ }^{3}$ do mesmo modo que a guerra endêmica entre êles, visando também a afirmação individual pela competição bélica foi substituída pela competição esportiva com a introdução do futebol. ${ }^{4} \mathrm{Em}$ ambos os casos o resultado positivo muito deveu ao trabalho dos antropólogos a serviço da administração colonial holandesa.

Como o avanço da civilização é inevitável, tais encontros e choques também o são.

Mas no encontro de tradições culturais distintas, como no caso que estamos vendo, a reformulação cultural não se dá apenas por perda, mas também por acréscimo de novos elementos. Muitas vêzes tais acréscimos, à semelhança do que se dá com a perda, são realizados mediante pressão e mesmo coercitivamente. Aqui outra vez está presente a Antropologia com princípios que descobriu no estudo da estabilidade e mudança cultural. Assim foi demonstrado que o que conta para a aceitação ou rejeição de um nôvo elemento cultural é o modo como os indivíduos do grupo receptor vêem o nôvo elemento; que a aceitação de um nôvo elemento é feita de maneira seletiva; que o nôvo elemento deve se ajustar à turma cultural na qual se pretende inseri-lo.

Os holandeses, quando pretenderam introduzir o uso de latrinas entre os já mencionados papuas, encontraram resistência, que segundo o antropólogo que trabalhava na área decorria do fato de terem a magia muito desenvolvida. Pensavam que as fezes poderiam ser usadas para magia negra de contágio. ${ }^{5}$

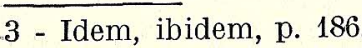

4 - Antropologia Cultural, Felix M. Keesing, 1ạ ed., 1961, Fundo de Cultura, p. 608.

5 - Idem, ibidem
Na Rósala o esforggo das autoridades para Lranaformarem tôdas as culturas dos diversos grupos étnieos que forman вав populaģăo, de modo a torná-las congruentes eom a teoria moelia lista, transformando-as em nacionais na forma e soelaliatai no conteúdo, num imenso trabalho de mudanęa eultural dirihldĭ, tem na contribuiçăo da Antropologia um suporte fundamental

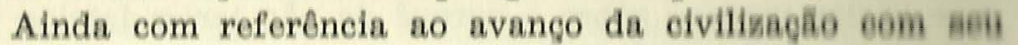
conhecimento cientifico e economia monetária é de fundamenta! importância uma constatação da pesquisa antropoloğle日̆, paiı uma avaliação e mesmo uma certa previsibilidade maí eomịls:

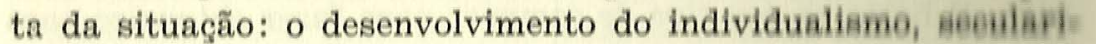
zação e desorganização cultural, nas sociedades que entram ยแก contato intimo com a civilização. ${ }^{7}$

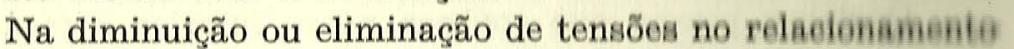
humano a Antropologia tem tido proficuo emprofgo, İ⿴囗十⺝ dee日iti sobretudo do conhecimento das motivações e valôres de e indivíduos que o método antropológico oportunian.

Durante a II Guerra mundial e depois com os problemai da ocupação, fêz parte integrante do treinamento do peasen! mi litar e administrativo, o estudo da personalidade modal a है nhecimento dos hábitos, valôres, normas de conduta de aliadoil e inimigos, a fim de que tivessem pontos de referênela parн вй

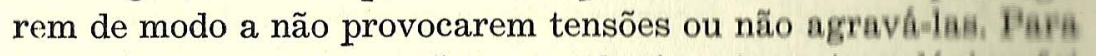
tais estudos e informações o conhecimento antropológleo fol decisivo. Uma vez que falamos em II Guerra é útil lembrą qие ela foi pródiga em oferecer campos para a aplicaçio do conhiิ cimentos antropológicos, desde um manual para identiflear plantas comestíveis até à guerra psicológica e mesmo na deelilio de preservar a monarquia japonêsa. ${ }^{8} \mathrm{Da}$ guerra resultarim, também, os estudos do caráter nacional, com fins eminentemen! te práticos.

Na busca do bem-estar vamos encontrar que o aumento di produtividade, a melhoria na alimentação, educação e condị̣̂ై

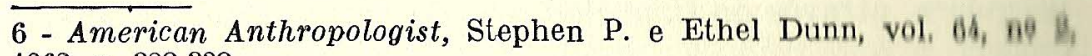
1962, p. 328-338.

7 - Yucatan, Robert Redifield, 1ạ ed., 1944, Fondo Económioo de Guliarị 8 - Kluckhohn, obra citada, p. 190. 
sanitárias, independente de qualquer etnocentrismo são vistas como fundamentais. Na realização de tais objetivos pode ser e è aplicada. Isto se dá porque em tais casos estão presentes problemas de valôres, de orientação cultural, de organização social, de crenças, com os quais a Antropologia tem intimidade.

Em pesquisa que realizamos no interior do Estado inquirimos várias pessoas sôbre o porquê de não terem latrina e as respostas obtidas indicavam que era algo supérfluo, já que havia árvores por perto das casas. Houve uma resposta que, além de corroborar as demais é significativa: «A tábua está muito cara, já basta as que tive de comprar para fazer chiqueiro para os porcos». A pessoa que deu essa resposta tinha uma situação econômica favorável.

Qualquer pessoa que conheça nosso interior notará que grande parte da população rural tem o hábito de consertar os dentes anteriores com ouro, por razões de prestígio, desprezando os posteriores que se tornam focos de infecção. Igualmente, pode ser constatado que amiùdamente o médico é procurado após o fracasso da benzedeira. Ainda no interior de nosso Estado um fato corriqueiro é as meninas não freqüentarem o colégio, porque seus pais, ou mais precisamente, o pai o julga desnecessário ou supõe ter a mulher pouca inteligência.

A subnutrição, decorrente de uma dieta mal balanceada, é outra característica comum no Estado. Numerosíssimas famílias não têm o hábito de cultivar e consumir legumes.

Problemas semelhantes encontramos em todo o mundo subdesenvolvido. Os pakot do Quênia resistiram de maneira definitiva aos esforços inglêses para melhorar seus rebanhos bovinos. O plano que visava diminuir o número de cabeças e melhorar a qualidade, fracassou devido ao sistema de valôres, normas legais, princípios de solidariedade e segurança social pakot que faz com que se interessem pelo número e não pela qualidade do gado, que é a base de sua economia. ${ }^{9}$

No Peru um plano que visava a melhoria na produção pesqueira, através do financiamento de barcos a motor e equi-

9--Continuity and Changing in African Cultures, 1a ed., 1959, The University of Chicago, Bascom e Herskovits (Ed.), cap. "Pakot Resistence to change". pamentos a baike eusto, fraeasaou, pois, pelas norman de aeli dariedade social do grupo em questlöo, um parente tinha a

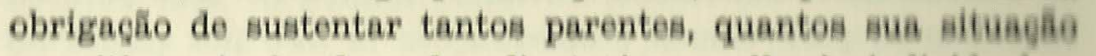
permitisse. Assim de nada adiantaria a melhoria individua, a menos que um individuo estivesse disposto a romper $60 m$ a ciedade e parentela. ${ }^{10}$

Em todos esses casos encontramos problemas de valôrea ; que muito interessam à Antropologia, st̆o atuantes $60 m$ mrandi pêso. A menos que se pretenda o emprêgo da fôrọa, o que

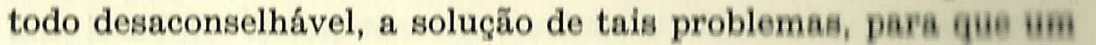
grande número de indivíduos se integre de modo global nä Fei: pectivas comunidades nacionais, implica, entre outrai numa reorganização cultural, numa reformulaĝ̣̆o de valôrei Aqui certamente a Antropologia estará presente. Nenhuma elän: cia sabe mais do que ela a respeito de valores e mudanęe eut tural.

Vejamos, através de dois casos concretos, como pode 60 ! correr positivamente para a solução de problemas đêsas tịpo.

No Chile um programa de saúde, que visava treinar milei nos problemas de cuidados com as crianças, obtinha um aiteei: so limitado. Um estudo da situação concluiu que tal oeorili pele fato do curso ser ministrado em salas de aula e a mie日 min tirem-se tratadas como alunas. A questão foi solucionadi 60 in encontros semanais, como se fôssem reuniões sociais, nai tea iali das que faziam o curso. ${ }^{11}$

Na Guatemala um programa que fornecia assistêneỉ mế dica totalmente gratuita não obtinha sucesso. Buscadal ai sas encontrou-se que a gratuidade causava suspeiçŭo quลnto A eficiência de médicos e medicamentos. A solução encontrada fol a cobrança de uma taxa simbólica, mas que tirava o earáter de gratuidade. $^{12}$

Também pode-se aplicar ùnicamente os métodos de peis quisa antropológica para estudar uma cultura o soeledade

10 - Traditional Cultures and the Impact of Theonologiont Ohamili George M. Foster, 1a ed., 1962, Harper \& Row Publishers, D. 09

11 - Idem, ibidem, p. 72.

12 - Idem, ibidem, p. 128-9. 
Isso é o que faz, para citar um único exemplo, o Departamento de Estado norte-americano, enviando muitos de seus futuros funcionários para cursos e observações in loco nos paises de sua futura atuação. Êste preparo é feito à base da observaçŭo participante.

Já foi dito anteriormente que a Antropologia é aplicada como ciência auxiliar. Assim ela é empregada em projetos e planejamentos mais ou menos globais, como projetos de reforma agrária, desenvolvimento econômico, colonização, redistribuição de população e outros. Recentemente elaborei um questionário para o Instituto Gaúcho de Reforma Agrária, num trabalho interdisciplinar que visava um levantamento, em vasta região do Estado, de dados para a elaboração de planos de reforma agrária.

O questionário pretendia fazer um levantamento de valôres e de alguns aspectos da organização e da orientação cultural nas diversas áreas a serem pesquisadas. Assim pretendia verificar se havia uma ligação sentimental com a terra ou se ela era vista sòmente como um bem econômico; atitude ante a presença de estranhos; a existência de uma orientação individualista, cooperativa ou competitiva; a presença e atuação de liderança; a cosmovisão, para servir de orientação àqueles que iriam planejar e executar os projetos de reforma. O questionário, entretanto, não chegou a ser aplicado por terem sido substituídos os responsáveis pelo projeto.

Para encerrar, cabe ainda abordar dois aspectos. O primeiro, se o antropólogo deve ou não participar ativamente do planejamento, da elaboração de planos e da política a ser seguida nos casos em que se emprega a Antropologia. Aqui as opiniões divergem. Dentre os renomados antropólogos que se opõem a essa participação na elaboração de uma política encontramos Evans-Pritchard, que defende o ponto de vista de que o antropólogo não pode se tornar um planejador e ainda continuar um cientista. Do lado oposto temos S. F. Nadel dizendo que se o conhecimento antropológico pode ser aplicado não há razão para impedir o antropólogo de ser um planejador ativo. ${ }^{13}$

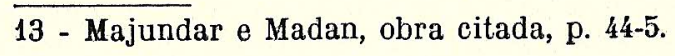

Filio-me ao segunde grupo aereseentande que em muitos

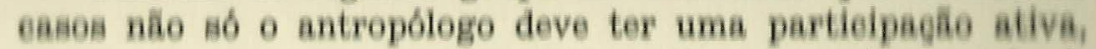

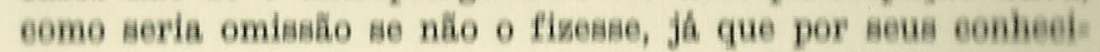

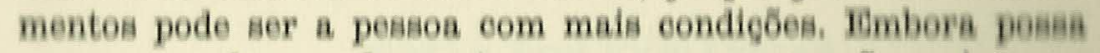
errar, suas chanees de acertar ou errar menos aerh๊o maiorea.

Finalmente, devo dizer alguma coisa a respeito de um ponto de primeira importancia, ou seja o que diz respeito a étiea e moral que deve presidir e orientar todo o trabalhe de Antre:

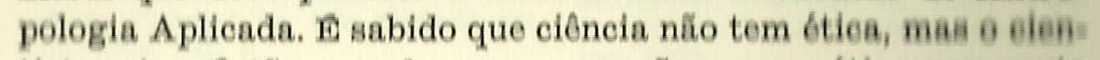
Uista, sim. E tão grande a preocupação com a étiea por parte dos antropólogos aplicados que a Sociedade de Antropolegiti Aplicada elaborou e publicou seu código de ótiea.

Dois problemas devem ser considerados aqui. Primeirei 0

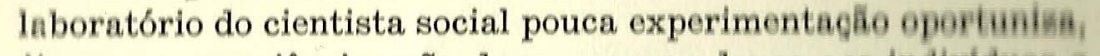
tha que as experiências não devem causar danos aos individuot e a comunidade que formam seu laboratório. O segunde e mai grave é que na aplicação da antropologia mais do que a meri constatação de alguma coisa visa-se modificar alguma celä

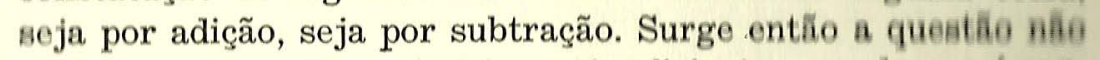
só de qual é o melhor, qual é o mais eficiente, mas do que ê êp: reto. Aqui o fôro íntimo do antropólogo é que val deeidis, tili pera-se que êle aja de acôrdo com seus princípios e que atuação esteja embasada no conhecimento cientifico e orientadi no interêsse dos indivíduos e da comunidade. 